Research Article

\title{
Organocatalytic Cascade Reaction of Aliphatic Enals and Benzoylnitromethane: Synthesis of Enantioenriched Tetrasubstituted Cyclohexene Carbaldehyde
}

\author{
Fredy A. David Rodriguez, ${ }^{1,2}$ Mauricio Maldonado Villamil $\left(\mathbb{D},{ }^{1}\right.$ \\ and James Guevara-Pulido ${ }^{2}{ }^{2}$ \\ ${ }^{1}$ Departamento de Química, Facultad de Ciencias, Universidad Nacional de Colombia-Sede Bogotá, Bogotá 11001, Colombia \\ ${ }^{2}$ Química Farmacéutica, Universidad El Bosque, Bogotá 11001, Colombia \\ Correspondence should be addressed to James Guevara-Pulido; joguevara@unbosque.edu.co
}

Received 21 April 2020; Accepted 5 June 2020; Published 28 June 2020

Academic Editor: Julia Revuelta

Copyright (c) 2020 Fredy A. David Rodriguez et al. This is an open access article distributed under the Creative Commons Attribution License, which permits unrestricted use, distribution, and reproduction in any medium, provided the original work is properly cited.

\begin{abstract}
A new example of the reactivity of enals with benzoylnitromethane was studied in a Michael-Michael-Aldol-Dehydration quadruple organocascade reaction. The reaction unexpectedly yielded a tetrasubstituted cyclohexene carbaldehyde with excellent enantiomeric excess when crotonaldehyde was used as the Michael-acceptor, whereas using (E)-Hex-2-enal as the Michaelacceptor formed a cyclic hemiacetal by steering the reaction into the intramolecular formation of the same intermediate via a Michael-Heterocyclization domino reaction.
\end{abstract}

\section{Introduction}

The design of synthetic strategies that result in highly functional and stereoselective organic compounds with consecutive stereocenters obtained through cascade reactions [1-11] are of great use in asymmetric synthesis as precursors of high added value molecules [12-14]. Cascade reactions are defined as "two or more bond-forming transformations which take place under the same reaction conditions, without adding additional reagents and catalysts, and in which the subsequent reactions result as a consequence of the functionality formed in the previous step" [15]. In the literature, biocatalysis and organometallic catalysis have been described as strategies currently used to carry out these types of reactions [16-22].

However, organocascade reactions have played an important role in the efficient production of highly complex chemical structures $[1,23]$. Organocatalysts are prolinesized organic molecules, often referred to as artificial enzymes, able to tolerate numerous functional groups and with the ability to be used under soft reaction conditions [1].
The latest advances in organocatalysis have demonstrated that the geometry of the iminium ion can be controlled in the stereoselective formation of carbon-carbon and carbon-heteroatom bonds [1, 11, 24-28]. Likewise, enamine activation has been shown to control the stereochemistry of alpha-functionalization of aldehydes and ketones with a variety of electrophiles [24, 29-31].

Based on previous examples, an important challenge in organocatalysis is the discovery of a simple organocatalyst able to promote stereoselective cascade reactions with high reaction yields. Studies have shown that these types of catalysts are suitable for the development of cascade reactions because they offer different, yet able to be combined, activation modes $[13,14,23,32]$. The quadruple cascade reaction $[9,33-35]$ is one recently described example of the efficiency of organocatalysts in stereocontrolled cascade reactions, where it was possible to obtain structures with high structural complexity. An interesting example is the formation of Michael adducts and their subsequent intramolecular cyclization, promoting the formation of cycles with consecutive stereocenters, which can be used as 
building blocks for more complex molecules. In this way, the influence of the $\mathrm{pKa}$ [36-40] of (pronucleophiles) is decisive in obtaining the type of product. For example, nucleophiles with $\mathrm{pKa}$ values of 9 used as Michael donors form Michael adducts that spontaneously cycle into hemiacetals via an intramolecular reaction [37], while nucleophiles with $\mathrm{pKa}$ of 10-14 lead to the formation of cyclic derivatives with a carbonyl function (Figure 1).

In the present investigation, organocatalysis and the influence of the $\mathrm{pKa}$ of benzoylnitromethane (pronucleophile) were evaluated in the reaction with crotonaldehyde and (E)-Hex-2-enal as starting reactants for the formation of Michael adducts and their subsequent intramolecular cyclization, promoting the formation of cycles with consecutive stereocenters, which can be used as building blocks for more complex molecules. The results showed that in addition to $\mathrm{pKa}$, the length of the alkyl chain of the unsaturated aldehyde is decisive for the type of cyclic system that can be obtained. The reaction conditions of the process were also studied and demonstrated that the reaction time is decisive in the formation of adducts.

\section{Materials and Methods}

2.1. General Experimental Information. IR spectra were recorded on a Thermo Fisher Scientific Nicolet iS10 FTIR spectrometer with a monolithic Diamond ATR accessory and absorption in $\mathrm{cm}^{-1}$ (Thermo Scientific, Waltham, MA, USA). ${ }^{1} \mathrm{H}$ and ${ }^{13} \mathrm{C}-\mathrm{NMR}$ spectra were recorded at $400 \mathrm{MHz}$ on a Bruker Avance 400 instrument. Chemical shifts are reported in ppm, using the solvent residual signal. Specific rotations were measured using a $1 \mathrm{~mL}$ cell with a $1 \mathrm{dm}$ path length, and a sodium lamp, and concentrations are given in $\mathrm{g} / 100 \mathrm{~mL}$. Chiral HPLC analysis was performed using Daicel Chiralcel OD Columns $(250 \times 4.6 \mathrm{~mm})$. UV detection was monitored at $256 \mathrm{~nm}$.

2.2. General Synthesis Method. Dichloromethane (10 mL), (R) $-(+)-\alpha, \quad \alpha$-diphenyl-2-pyrrolidinemethanol trimethylsilyl ether (Hayashi-Jørgensen catalyst) (15 mol\%), and benzoic acid (cocatalyst) (15 mol\%) were added to a solution of benzoylnitromethane $(0.10 \mathrm{mmol})$ and crotonaldehyde $(0.30 \mathrm{~mol})$. The reaction was carried out at room temperature under constant stirring until the reaction ended. The products were purified by column chromatography using a hexane-ethyl acetate mixture (95: 5). TLC analysis was carried out on aluminum-backed plates coated with silica gel 60 and an indicator F254, and the plates were visualized with UV light.

2.2.1. Synthesis of 4-Benzoyl-4-Nitro-3,5-Dipropylheptanedial. (3a) A colorless oil with a $15 \%$ yield was obtained in $6 \mathrm{~h} ;{ }^{1} \mathrm{H}$ NMR $\left(400 \mathrm{MHz}, \mathrm{CDCl}_{3}\right) \delta 9.97$ (s ancho, 2H), 7.79-7.77 (m, $2 \mathrm{H})$ ), 7.62-7.58 (m, 1H), 7.51-7.47 (m, 2H), 2.45-2.43 (m, $2 \mathrm{H}), 1.29-1.23(\mathrm{~m}, 4 \mathrm{H}), 1.07(\mathrm{~d}, J=6.9 \mathrm{~Hz}, 3 \mathrm{H}), 0.96(\mathrm{~d}$, $J=7.1 \mathrm{~Hz}, 3 \mathrm{H})$.
2.2.2. Synthesis of 5-Benzoyl-4,6-Dimethyl-5-Nitrocyclohex1-Enecarbaldehyde. (3b) A colorless oil with an $18 \%$ yield was obtained in $6 \mathrm{~h} ;[\propto]_{D}^{20}=+199\left(c=0.55, \mathrm{CHCl}_{3}, 96 \%\right.$ ee $)$ ${ }^{1} \mathrm{H} \mathrm{NMR}\left(400 \mathrm{MHz}, \mathrm{CDCl}_{3}\right) d \delta 9.51(\mathrm{~s}, 1 \mathrm{H}), 7.82(\mathrm{dd}, J=8.4$, $1.2 \mathrm{~Hz}, 2 \mathrm{H}), 7.59$ (t, $J=7.4 \mathrm{~Hz}, 1 \mathrm{H}), 7.45$ (brt, $J=8.4,7.2 \mathrm{~Hz}$, $2 \mathrm{H}), 6.80(\mathrm{dd}, J=5.0,2.6 \mathrm{~Hz}, 1 \mathrm{H}), 3.90(\mathrm{q}, J=6.8 \mathrm{~Hz}, 1 \mathrm{H})$, $3.00(\mathrm{dp}, J=12.1,6.2 \mathrm{~Hz}, 1 \mathrm{H}), 2.69(\mathrm{dt}, J=20.7,5.3 \mathrm{~Hz}, 1 \mathrm{H})$, $2.02-1.93(\mathrm{~m}, 1 \mathrm{H}), 1.18(\mathrm{~d}, J=6.4 \mathrm{~Hz}, 3 \mathrm{H}), 0.93(\mathrm{~d}, J=7.2 \mathrm{~Hz}$, $3 \mathrm{H}) ;{ }^{13} \mathrm{C} \mathrm{NMR}(101 \mathrm{MHz}, \mathrm{CDCl} 3) \delta 192.5,189.7,147.4$, 142.8, 134.6, 134.0, 129.2, 127.9, 99.8, 34.2, 31.0, 22.8, 17.3, 16.9.; HPLC (Chiralcel OD-H hexane/EtOH $=98: 2,1.0 \mathrm{~mL} /$ $\min , \lambda=256 \mathrm{~nm}$ ) $t_{\mathrm{R}}=6.8 \mathrm{~min}$ (minor), $t_{\mathrm{R}}=7.9$ (major).

2.3. Synthesis of 3-(1-Nitro-2-Oxo-2-Phenylethyl) Hexanal. (3c) Dichloromethane $(10 \mathrm{~mL}),(\mathrm{R})-(+)-\alpha, \alpha$-diphenyl-2pyrrolidinemethanol trimethylsilyl ether (HayashiJørgensen catalyst) (15 mol\%) and benzoic acid (cocatalyst) $(15 \mathrm{~mol} \%)$ were added to a solution of benzoylnitromethane $(0.10 \mathrm{mmol})$ and $(E)$-Hex-2-enal $(0.10 \mathrm{~mol})$. The reaction was carried out at room temperature under constant stirring until the reaction ended. The products were purified by column chromatography using a hexane-ethyl acetate mixture (95:5). TLC analysis was carried out on aluminumbacked plates coated with silica gel 60 and an indicator F254, and the plates were visualized with UV light.

A colorless oil with a $17 \%$ yield was obtained in $4 \mathrm{~h} ;{ }^{1} \mathrm{H}$ $\operatorname{NMR}\left(400 \mathrm{MHz}, \mathrm{CDCl}_{3}\right) \delta 9.77(\mathrm{t}, J=1.0 \mathrm{~Hz}, 1 \mathrm{H}), 8.13-8.10$ $(\mathrm{m}, 2 \mathrm{H}), 7.63-7.59(\mathrm{~m}, 1 \mathrm{H}), 7.50-7.45(\mathrm{~m}, 2 \mathrm{H}), 4.44(\mathrm{dd}$, $J=6.0,1.0 \mathrm{~Hz}, 1 \mathrm{H}), 2.76-2.68(\mathrm{~m}, 1 \mathrm{H}), 2.69-2.54(\mathrm{~m}, 2 \mathrm{H})$, $1.44-1.31(\mathrm{~m}, 4 \mathrm{H}), 0.92(\mathrm{t}, J=6.9 \mathrm{~Hz}, 3 \mathrm{H})$.

2.4. Synthesis of 2-Ethoxy-5-Nitro-6-Phenyl-4-Propyl-3,4-Dihydro-2H-Pyran. (3e) Dichloromethane $(10 \mathrm{~mL}),(\mathrm{R})-(+)-\alpha$, $\alpha$-diphenyl-2-pyrrolidinemethanol trimethylsilyl ether (Hayashi-Jørgensen catalyst) $(15 \mathrm{~mol} \%)$ and benzoic acid (cocatalyst) (15 mol\%) were added to a solution of benzoylnitromethane $(0.10 \mathrm{mmol})$ and (E)-Hex-2-enal $(0.30 \mathrm{~mol})$. The reaction was carried out at room temperature under constant stirring until the reaction ended. The products were purified by column chromatography using a hexane-ethyl acetate mixture (95: 5). TLC analysis was carried out on aluminum-backed plates coated with silica gel 60 and an indicator F254, and the plates were visualized with UV light.

A colorless oil with a $30 \%$ yield was obtained in $6 \mathrm{~h}$; $[\propto]_{D}^{20}=+2.8\left(c=0.65, \mathrm{CHCl}_{3}, 68 \%\right.$ ee $){ }^{1} \mathrm{H} \mathrm{NMR}(400 \mathrm{MHz}$, $\left.\mathrm{CDCl}_{3}\right) \delta 8.10-8.05(\mathrm{~m}, 2 \mathrm{H}), 7.59(\mathrm{t}, J=7.4 \mathrm{~Hz}, 1 \mathrm{H}), 7.47(\mathrm{t}$, $J=7.7 \mathrm{~Hz}, 2 \mathrm{H}), 6.18(\mathrm{dd}, J=6.0,4.0 \mathrm{~Hz}, 1 \mathrm{H}), 4.56(\mathrm{dd}$, $J=12.3,6.1 \mathrm{~Hz}, 1 \mathrm{H}), 4.37(\mathrm{dd}, J=12.3,7.2 \mathrm{~Hz}, 1 \mathrm{H}), 3.79(\mathrm{dq}$, $J=9.5,7.1 \mathrm{~Hz}, 1 \mathrm{H}), 3.62(\mathrm{dq}, J=9.5,7.1 \mathrm{~Hz}, 1 \mathrm{H}), 2.59-2.48$ $(\mathrm{m}, 1 \mathrm{H}), 2.05-1.81(\mathrm{~m}, 2 \mathrm{H}), 1.48-1.34(\mathrm{~m}, 2 \mathrm{H}), 1.23(\mathrm{t}$, $J=7.2 \mathrm{~Hz}, 3 \mathrm{H}), 0.91(\mathrm{t}, J=7.0 \mathrm{~Hz}, 3 \mathrm{H}) ;{ }^{13} \mathrm{C} \mathrm{NMR}(101 \mathrm{MHz}$, $\left.\mathrm{CDCl}_{3}\right) \delta 166.1,133.4,129.8,129.7,128.5,97.3,79.5,79.3$, 65.3, 36.0, 34.0, 33.2, 15.0, 13.9: HPLC (Chiralcel OD-H, hexane $/ \mathrm{EtOH}=95: 5,1.0 \mathrm{~mL} / \mathrm{min}, \lambda=256 \mathrm{~nm}) t_{\mathrm{R}}=1.7 \mathrm{~min}$ (minor), $t_{\mathrm{R}}=2.8 \mathrm{Min}$ (major); IR $\left(\mathrm{ATR} / \mathrm{cm}^{-1}\right.$ ) 2928, 2257, 1715, 1550. 1379, 1271. 


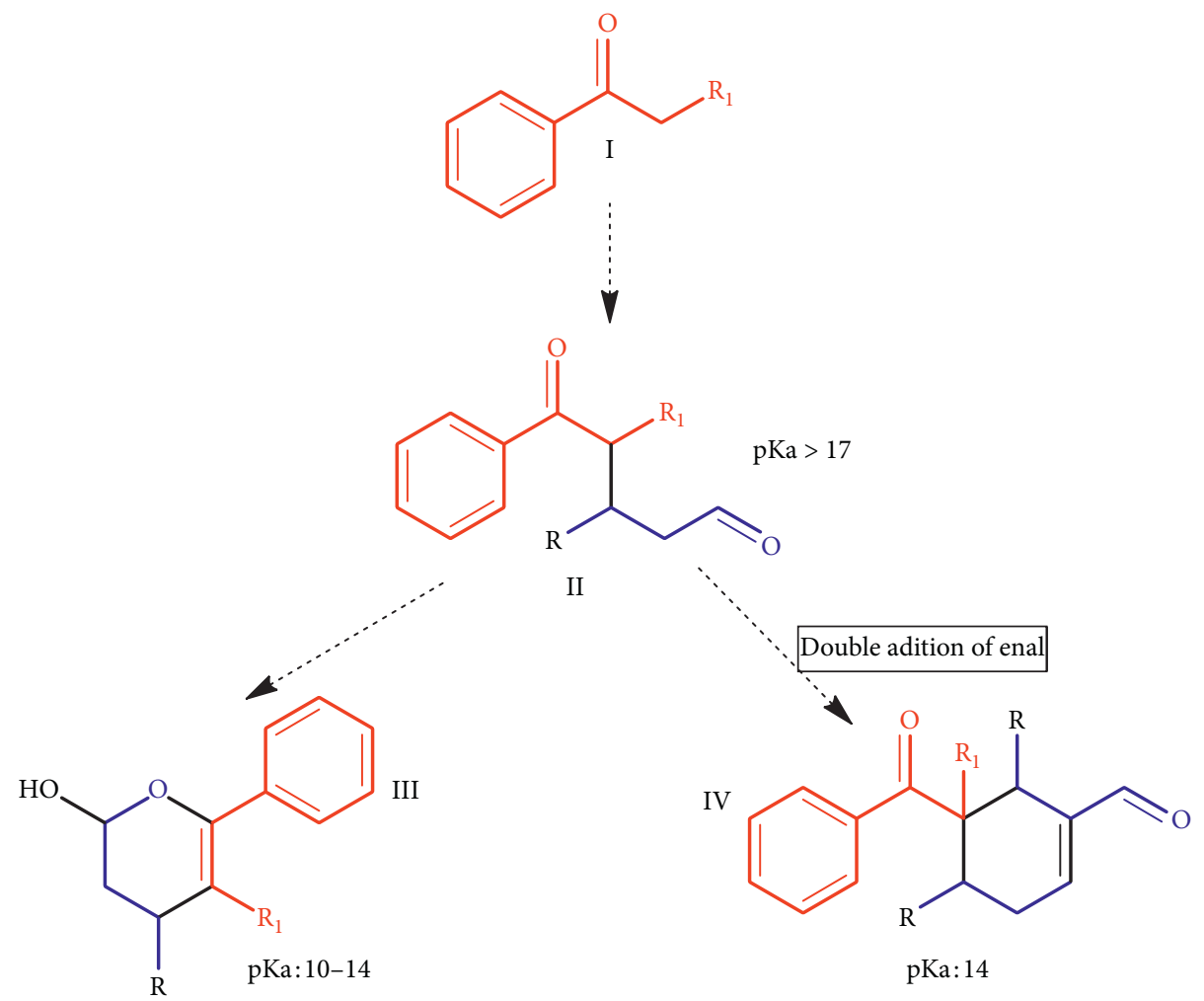

Figure 1: Possible structures that can be obtained by the Michael donor pKa value.

\section{Results and Discussion}

As mentioned above, for the present study, we chose benzoylnitromethane (1a) as the pronucleophile in the organocatalyzed Michael addition, which is an adequate model for the evaluation of the reaction conditions and the chirality that the process involves. Additionally, Crotonaldehyde and $(E)$ Hex-2-enal were used as $\mathrm{Mi}$ chael-acceptor while (A) (R)-(+) - $\alpha, \alpha$-diphenyl-2pyrrolidinemethanol trimethylsilyl ether (otherwise known as the Hayashi-Jørgensen catalyst) and (B) proline were used as catalysts, where the latter served as a bifunctional catalyst activating both enals and nitroketones. The first step of the study involved the reaction between 1a and crotonaldehyde (2a), initially following the method as described in the literature [38]. TLC analysis of the reaction showed the formation of two products; these derivatives were purified by column chromatography and characterized via spectral techniques, including ${ }^{1} \mathrm{H}-\mathrm{NMR}$, ${ }^{13} \mathrm{C}-\mathrm{NMR}$, and 2D-NMR experiments (see Supplementary Materials (available here)).

In this way, the first additional product of 1 a with $2 \mathrm{a}$ showed that the ${ }^{1} \mathrm{H}$-NMR spectrum displayed characteristic signals of aldehyde at $9.97 \mathrm{ppm}$ and for alkyl chains signals at 0.96 and $1.07 \mathrm{ppm}$ for methyl groups, $1.29 \mathrm{ppm}$ for the methylene group, and for the methine group the signal was observed at $2.44 \mathrm{ppm}$. Aromatic protons were observed at $7.78,7.60$, and $7.49 \mathrm{ppm}$. The integral of these signals was for five protons in the aromatic ring, and for aldehyde, it was for two protons, indicating that the Michael addition reaction occurred with two molecules of the unsaturated aldehyde, allowing the formation of adduct 3a (Scheme 1). The confirmation of this result is evident with the disappearance of the signals at 4.00-4.50 ppm, which confirmed the formation of the adduct. Unfortunately, this product was very unstable and could not be fully characterized. The second derivative, $\mathbf{3 b}$, was obtained as a colorless and viscous liquid. The ${ }^{1} \mathrm{H}-\mathrm{NMR}$ spectrum displayed downfield signals at $9.97 \mathrm{ppm}$, attributed to one proton of the aldehyde group, at $7.82,7.59$, and $7.45 \mathrm{ppm}$ for the aromatic protons (integral for one aromatic ring) and at $6.80 \mathrm{ppm}$, which is a characteristic of a vinyl proton. In this sense, the decrease in the integral of the aldehyde signals is indicative of the formation of an unsaturated ring, which was confirmed with two groups of signals: first, the signals for diastereotopic protons of the methylene group in the cycle at 2.69 and $2.02 \mathrm{ppm}$, and second, the signal at $3.00 \mathrm{ppm}$. Finally, in the ${ }^{1} \mathrm{H}-\mathrm{NMR}$ spectrum, the signal at $3.90 \mathrm{ppm}$ was attributed to the methine in the cycle, which, coupled with the signal at $1.18 \mathrm{ppm}$, was attributed to the methyl group in the cycle. The ${ }^{13} \mathrm{C}-\mathrm{NMR}$ spectrum showed fourteen signals, which are expected to compound, from these displayed characteristic signals of ketone and aldehyde groups at 192.5 and $189.7 \mathrm{ppm}$, respectively. The aromatic carbons appeared at $127-134.6 \mathrm{ppm}$ and the vinyl carbons at 147.4 and $142.8 \mathrm{ppm}$. In this way, the signal at $99.8 \mathrm{ppm}$ confirmed the presence of a tetrasubstituted carbon linked to the nitro group, and the number of signals in the aliphatic region consisted of the structure of the unsaturated cycle (Scheme 1). Once the chemical identity of the majority products of the reaction was established, the best reaction conditions were evaluated (Table 1). 


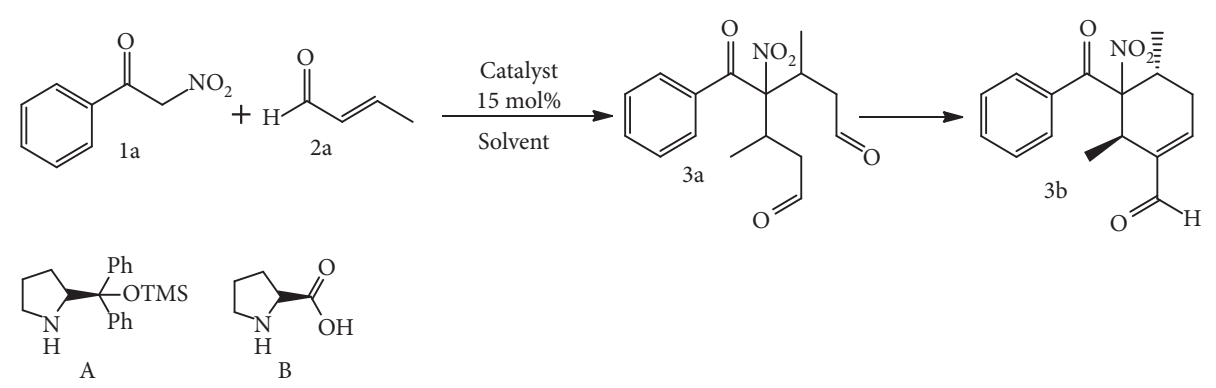

Scheme 1: Reaction conditions screening for benzoylnitromethane-crotanaldehyde Michael addition.

TABLE 1: Influence of solvent, stoichiometric ratio, catalyst, and cocatalyst in the 1a to 2a Michael addition.

\begin{tabular}{|c|c|c|c|c|c|c|c|}
\hline Entry & Catalyst & Solvent & Cocatalyst & Ratio & Time (h) & Yield $(\%)^{\mathrm{a}}$ & $\mathrm{Ee} \%^{\mathrm{b}}$ \\
\hline 1 & $\mathrm{~B}$ & DCM & - & $1: 1$ & 4 & 8 & $\mathrm{Nd}$ \\
\hline 2 & B & DCM & - & $1: 2$ & 3 & 12 & $\mathrm{Nd}$ \\
\hline 3 & $\mathrm{~B}$ & $\mathrm{CHCl}_{3}$ & - & $1: 1$ & 4 & 10 & $\mathrm{Nd}$ \\
\hline 4 & B & $\mathrm{CHCl}_{3}$ & - & $1: 2$ & 3 & 11 & $\mathrm{Nd}$ \\
\hline 5 & B & Hexane & - & $1: 1$ & 10 & No rxn & - \\
\hline 6 & $\mathrm{~B}$ & Toluene & - & $1: 1$ & 10 & No rxn & - \\
\hline 7 & B & $\mathrm{Et}_{2} \mathrm{O}$ & - & $1: 1$ & 10 & No rxn & - \\
\hline 8 & B & $\mathrm{EtOH}$ & - & $1: 1$ & 4 & Complex mixture & - \\
\hline 9 & $\mathrm{~B}$ & DMSO & - & $1: 1$ & 4 & Complex mixture & - \\
\hline 10 & A & DCM & $\mathrm{Bac}$ & $1: 1$ & 7 & 25 & 93 \\
\hline 11 & $\mathrm{~A}$ & DCM & $\mathrm{Bac}$ & $1: 2$ & 6 & 30 & 93 \\
\hline 12 & A & DCM & $\mathrm{Bac}$ & $1: 3$ & 6 & 40 & 96 \\
\hline 13 & A & $\mathrm{CHCl}_{3}$ & $\mathrm{Bac}$ & $1: 1$ & 6 & 20 & 90 \\
\hline 14 & $\mathrm{~A}$ & $\mathrm{CHCl}_{3}$ & $\mathrm{Bac}$ & $1: 3$ & 6 & 30 & 92 \\
\hline 15 & A & $\mathrm{DCM}$ & - & $1: 3$ & 19 & 35 & 80 \\
\hline
\end{tabular}

${ }^{a}$ Yield refers to the isolated compound. ${ }^{\mathrm{b}}$ The percentages were determined by chiral HPLC. All entries were carried out at room temperature

During the first set of trials, the influence of the solvent, catalyst, cocatalyst, and the stoichiometric relationship of the reactants were evaluated in order to pinpoint the necessary reaction conditions for obtaining high yields of product $\mathbf{3 b}$. Table 1 illustrates the most relevant results.

Results show that pairing catalyst B with most of the solvents used either resulted in complex mixtures or exhibited no reaction at all when examined with TLC. However, using catalyst B with halogenated solvents (entries 1 and 3, Table 1) yielded a majority of one product, which was later purified by column chromatography and identified as product $\mathbf{3 b}$. Based on these results, the influence of the stoichiometric ratio of reactants was studied next (entries 2 and 4, Table 1), where it was discovered that the reaction yield of product $3 \mathbf{b}$ increased when the ratio of $2 \mathrm{a}$ was increased. Then catalyst A and cocatalyst BAc (benzoic acid) were paired only with the halogenated solvents. Entries 10-14, Table 1, show that the percentage yield of product $\mathbf{3 b}$ and the rate of the reaction increased significantly. According to these results, the best reaction conditions for the formation of $\mathbf{3 a}$ were determined to be those present in entry 12, Table 1. It is important to highlight the fact that this product is described in the literature as the first example where a cyclohexene carbaldehyde with consecutive chiral centers, one of which is a quaternary carbon center, was obtained via organocatalysis.
Once the reaction conditions were optimized, the reactivity of aliphatic enals such as $2 \mathrm{~b}$ was evaluated in order to determine if the reaction could also be used with longerchain enals. Surprisingly, the reaction did not occur as expected, since it yielded two different products (3c and $\mathbf{3 d}$ ) in 20 hours. Each product was isolated, but only 3d was completely characterized (Schemes 2 and 3).

The first product of 1a with (E) Hex-2-enal (2b) is showed in the ${ }^{1} \mathrm{H}-\mathrm{NMR}$ spectrum signals of the aliphatic chain at $0.92,1.38,2.63$, and $2.72 \mathrm{ppm}$. The characteristic signal at $4.44 \mathrm{ppm}$ was attributed to the hydrogen of the methine group attached to the nitro group. In addition, aromatic protons were observed in the region of 7.45-750, 7.59-7.63, and 8.10-8.13 ppm. Finally, the ${ }^{1} \mathrm{H}-\mathrm{NMR}$ spectrum displayed characteristic signals of aldehyde at $9.97 \mathrm{ppm}$. In this way, the ratio of integrals between the aldehyde hydrogen and the five signals in the aromatic region indicated that Michael's additional reaction occurred with one molecule of the unsaturated aldehyde, and this is consistent with the signals of adduct $3 \mathbf{c}$ (Scheme 2). In order to confirm the above assignments, the ${ }^{1} \mathrm{H}_{-}{ }^{1} \mathrm{H}$ COSY spectrum was recorded. The correlations for $3 \mathrm{c}$ are given in Table 2; the observed ${ }^{1} \mathrm{H}-{ }^{1} \mathrm{H}$ COSY correlations confirm the connectivity and the assignments made. Similarly to adduct 3a, the stability of $\mathbf{3 c}$ was not stable enough to characterize.

In order to characterize the product of the cyclization, the reaction was carried out for a longer period of time until 


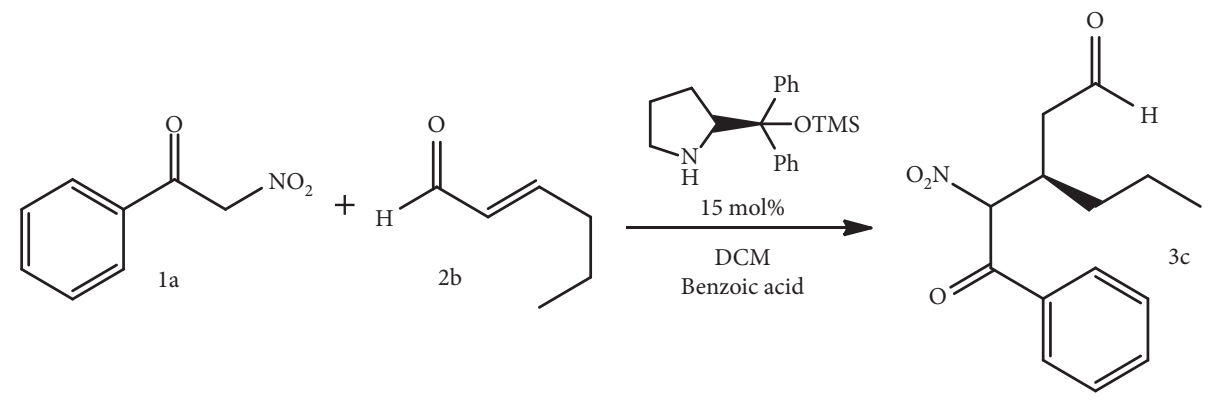

Scheme 2: Formation of reaction intermediate $3 \mathbf{c}$.

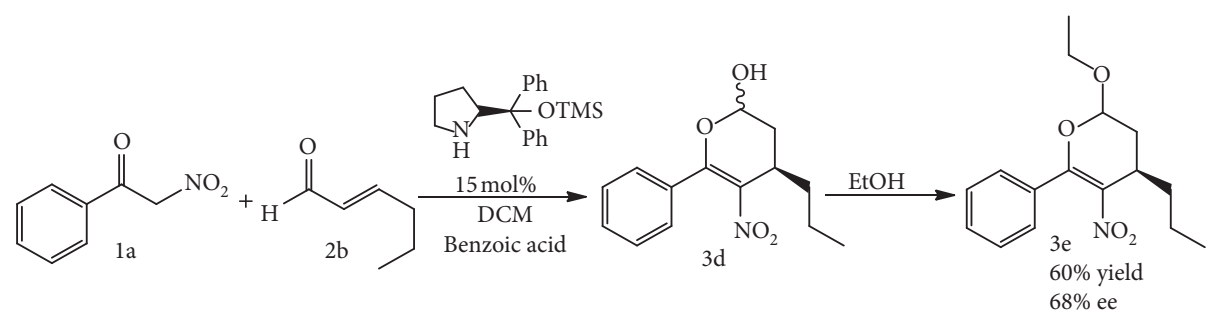

Scheme 3: Michael-heterocyclization-acetylation domino reaction.

TABLE 2: Correlations for compound Michael adduct $3 c$ in the COSY spectrum.

\begin{tabular}{lcc}
\hline Proton & $\delta(\mathrm{ppm})$ & Correlation \\
\hline 1 & 0.92 & $2(1.44-1.31)$ \\
2 & $1.44-1.31$ & $1(0.92), 2(1.44-1.31), 4(2.76-2.68)$ \\
3 & $2.69-2.54$ & $4(2.71), 9(9.77)$ \\
4 & $2.76-2.68$ & $2(1.44-1.31), 3(2.69-2.54), 5(4.44)$ \\
5 & 4.44 & $4(2.76-2.68)$ \\
6 & $7.50-7.45$ & $7(7.63-7.59), 8(8.13-8.10)$ \\
7 & $7.63-7.59$ & $6(7.50-7.45)$ \\
8 & $8.13-8.10$ & $6(7.50-7.45)$ \\
9 & 9.97 & $3(2.69-2.54)$ \\
\hline
\end{tabular}

TLC showed that product $3 \mathrm{c}$ had disappeared from the reaction mixture. After 30 hours, $3 \mathbf{b}$ had disappeared. Later, purification by column chromatography of the majority product was carried out. As shown in Table 3, signals of ${ }^{13} \mathrm{C}$ NMR and ${ }^{1} \mathrm{H}-\mathrm{NMR}$ were unambiguously assigned through 1D- and 2D-NMR experiments, including the HMQC and HMBC spectra. The ${ }^{13} \mathrm{C}-\mathrm{NMR}$ spectrum shows a signal at 79.3 ppm with no correlation in the HSQC spectrum. In the HMBC spectrum, this signal shows a correlation with the methyl protons $4 \mathrm{a}, \mathrm{b}$ (see Figure 2 and Table 3 ) at $1.81-2.05 \mathrm{ppm}$ and with the signal at $2.50 \mathrm{ppm}$; hence these signals must be due to diastereotopic protons of $\mathrm{CH}_{2}$ of the cyclic acetal ring. There is a weak signal at $166.1 \mathrm{ppm}$. This signal has no correlation with the HMQC spectrum and was attributed to vinyl carbon because of its connectivity with proton 8 . In the HMBC spectrum, the signal at $33.2 \mathrm{ppm}$ exhibits a correlation with the diastereotopic methylene group protons $7 \mathrm{a}$ and $7 \mathrm{~b}$ at 4.37 and $4.56 \mathrm{ppm}$. An important piece of evidence of acetal formation can be seen in the HMBC spectrum through the signal at $97.3 \mathrm{ppm}$, which exhibits a correlation with the diastereotopic methylene group protons at $1.81-2.05 \mathrm{ppm}$ and the correlations with the proton (5) at $2.48-2.59 \mathrm{ppm}$.

Previous literature has mentioned this Michael addition product $(3 \mathbf{c})$ as a reaction intermediate, although not when nucleophiles like 1a with pKa values of 7.7 were used. This is attributable to the fact that increasing the acidity of the ketone's $\alpha$-protons induces the spontaneous cyclization of the Michael adduct into cyclic hemiacetals or into 3-hydroxy-cyclohexanones [38]. Instances where the Michael adduct is stable and does not spontaneously cycle have been documented, but only when the pKa of the ketone's $a$-protons remains close to 19 , as described by $[37,39]$.

In order to characterize product $\mathbf{3 c}$, the reaction was carried out for a longer period of time until TLC showed that product $\mathbf{3 b}$ had disappeared from the reaction mixture. After 30 hours, $3 \mathrm{c}$ had disappeared, but upon purification by column chromatography, product $\mathbf{3 d}$ decomposed. The literature states that nucleophiles with $\mathrm{pK}_{\mathrm{a}}$ values of 9 used as Michael donors form Michael adducts that spontaneously cycle into hemiacetals via an 
TABLE 3: Correlations for $3 c$ in the HSQC and HMBC spectra.

\begin{tabular}{lccc}
\hline Carbon & $\delta(\mathrm{ppm})$ & Correlation HSQC & Correlation HMBC \\
\hline 1 & 13.9 & $1(0.90)$ & $3(1.48-1.34)$ \\
2 & 15.0 & $2(1.23)$ & $6 \mathrm{a}(3.62), 6 \mathrm{~b}(3.79)$ \\
3 & 33.2 & $5(2.59-2.48)$ & $3(1.48-1.34), 4 \mathrm{a}, \mathrm{b}(2.05-1.81), 7 \mathrm{a}(4.37), 7 \mathrm{~b}(4.56), 8(6.18)$ \\
4 & 33.9 & $3(1.48-1.34)$ & $1(0.90), 5(2.59-2.48), 7 \mathrm{a}(4.37), 7 \mathrm{~b}(4.56)$ \\
5 & 35.6 & $4 \mathrm{a}, \mathrm{b}(2.05-1.81)$ & $5(2.59-2.48), 7 \mathrm{a}(4.37), 7 \mathrm{~b}(4.56)$ \\
6 & 63.3 & $6 \mathrm{a}(3.62), 6 \mathrm{~b}(3.79)$ & $2(1.23), 8(6.18)$ \\
7 & 79.3 & $7 \mathrm{a}(4.37), 7 \mathrm{~b}(4.56)$ & $4 \mathrm{a}, \mathrm{b}(2.05-1.81), 5(2.59-2.48)$ \\
8 & 79.5 & $8(6.18)$ & $4 \mathrm{a}, \mathrm{b}(2.05-1.81)$ \\
9 & 97.3 & $9(7.47)$ & $4 \mathrm{a}, \mathrm{b}(2.05-1.81), 5(2.59-2.48), 6 \mathrm{a}(3.62), 6 \mathrm{~b}(3.79)$ \\
10 & 128.5 & - & $10(7.59)$ \\
11 & 129.7 & $11(8.10-8.05)$ & $9(7.47), 11(8.10-8.05)$ \\
12 & 129.8 & $10(7.59)$ & $9(7.47), 10(7,59)$ \\
13 & 133.4 & - & $11(8.10-8.05)$ \\
14 & 166.1 & & $8(6.18), 11(8.10-8.05)$
\end{tabular}

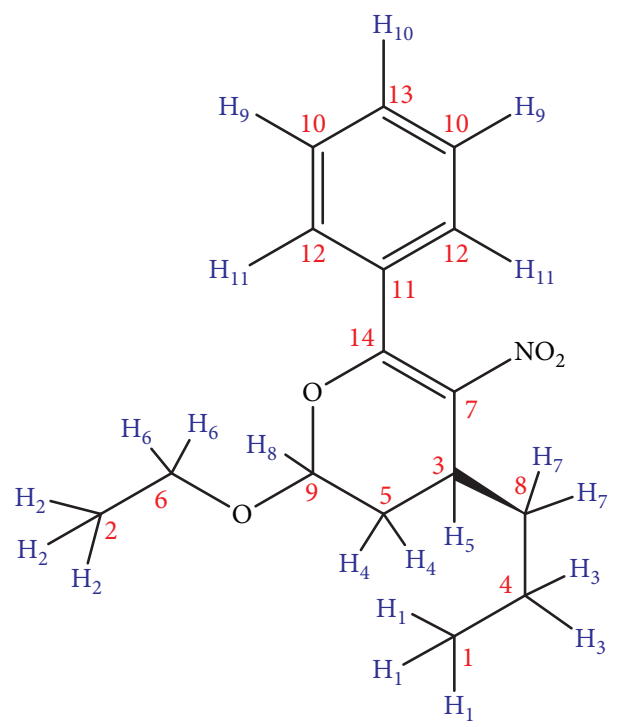

FIgURE 2: Structure and assignment of the proton and carbon signals of compound $\mathbf{3 e .}$

intramolecular reaction [37]. These studies have shown that these adducts should be oxidized or reduced in situ into pyranone or pyran derivatives, respectively, in order to avoid the compound's hydrolysis in the reaction medium. In the present project, ethanol was used as the nucleophile to form the alkyl derivative $3 \mathbf{e}$ in order to stabilize and therefore be able to quantify and elucidate the structure of $3 \mathbf{d}$ (Scheme 3).

Activation of the enal and the addition of the nucleophile follow the general path previously described by [41-44]. This means that the stereochemistry of the final product is dictated by the $\beta$-attack of the nucleophile from the less-hindered Re-face of the iminium ion.

Synthesis of product $\mathbf{3 b}$ is described as a MichaelMichael-aldol-dehydration quadruple domino reaction. The first addition on the $\alpha$-carbon by 2 a occurs via the iminium ion. Once the monoadduct is obtained, the second Michael addition by an additional 2a molecule immediately takes place, obtaining 3a. Additionally, during this secondary catalytic cycle by activation via iminium ion, the monoadduct becomes an enolizable nucleophile. This secondary cycle yields 3a (Scheme 4). Subsequently, this diadduct enters another cycle started off by an intramolecular aldol reaction prompted by enamine activation. Then condensation of $\mathbf{3 a}$ and $\mathrm{B}$ generates an iminium ion 9 which tautomerizes into enamine 10 . Next, the enamine 10 's $\alpha$-carbon attacks its carbonyl carbon, yielding the cyclic intermediate 11 . The hydrolysis of this intermediate forms aldol product 12 , which, as described in the literature $[13,27]$, undergoes rapid dehydration prompted by Bac, finally yielding compound $\mathbf{3 b}$.

On the other hand, the synthesis of $\mathbf{3} \mathbf{e}$ is described as a Michael-heterocyclization-acetalization domino reaction that involves activation modes via the iminium ion through the same intermediate reaction towards the formation of product $\mathbf{3 b}$ (Scheme 3) (Scheme 4). However, this catalytic cycle does not undergo the double Michael addition that resulted in $\mathbf{3} \mathbf{a}$, allowing instead the isolation and purification of Michael monoadduct 3c. 


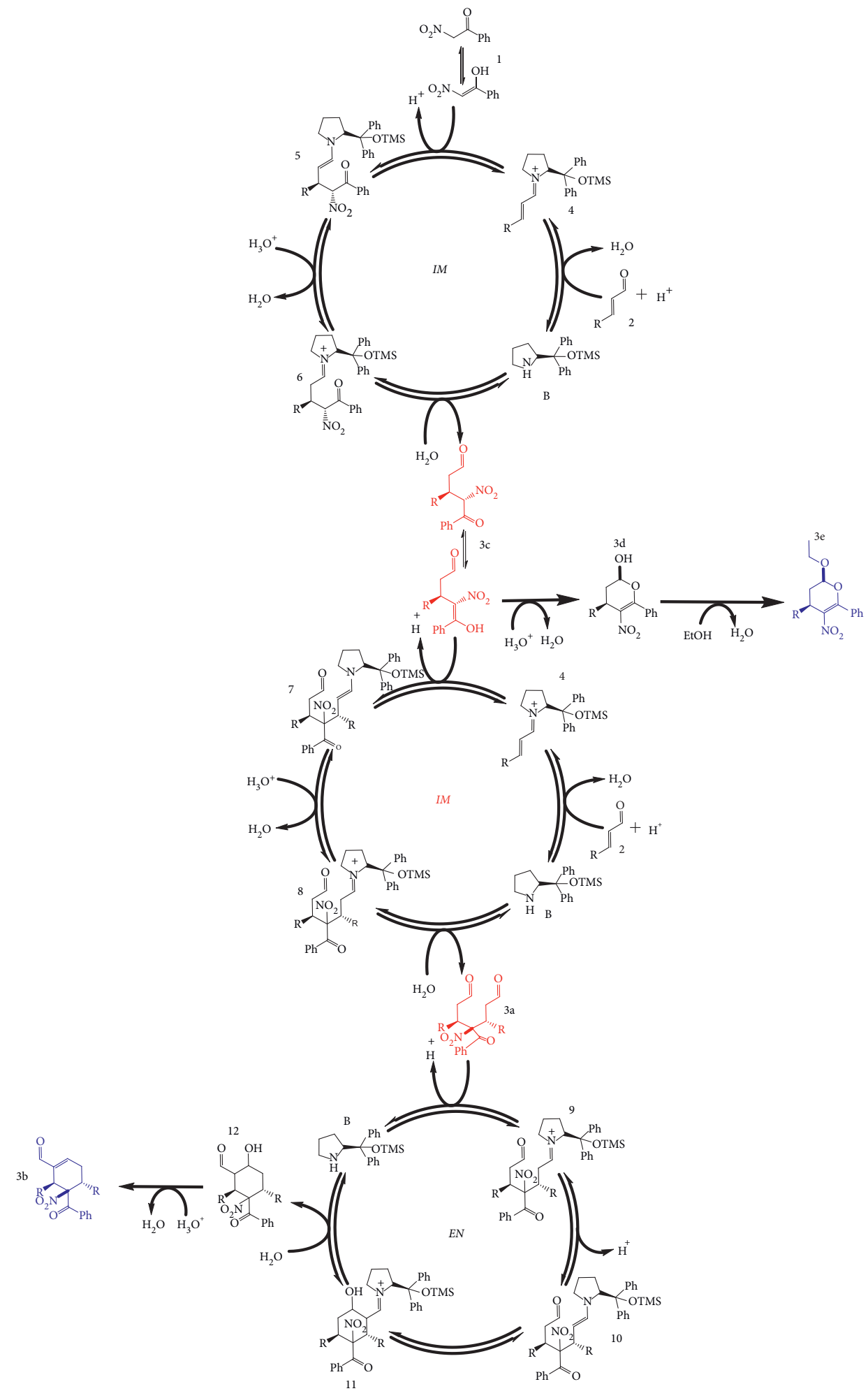

SCHeme 4: Proposed mechanism for the organocatalytic synthesis of $\mathbf{3 a}, \mathbf{3 b}, \mathbf{3} \mathbf{c}, \mathbf{3 d}$, and $\mathbf{3 e}$.

This intermediate reacts intramolecularly, yielding hemiacetal $3 \mathbf{d}$ by a 1,2-addition-mediated heterocyclization. Finally, due to the hemiacetal's instability in the one-pot reaction medium $3 \mathbf{e}$ was generated by the addition of ethanol.

\section{Conclusions}

Based on background information related to organocatalytic domino reactions, especially those involving Michael additions featuring the use of ketones with active hydrogens as 
nucleophiles, it was established that using a nucleophile with $\mathrm{pKa}$ values of 7.7, such as benzoylnitromethane, yields intermediate Michael adducts that, depending on the number of carbon atoms of the enal used, form a tetrasubstituted cyclohexene carbaldehyde with an excellent enantiomeric excess as a product of a Michael-Michael-aldol-dehydration quadruple cascade reaction when crotonaldehyde is used as the enal. Concurrently, when $(E)$-Hex-2-enal is used as the enal, the reaction occurs via a Michael-heterocyclizationacetylation domino reaction with a moderate enantiomeric excess. Moreover, as expected, the results show the effectiveness of a ketone with pKa values of 7.7 as the Michael donor, which contrasts with the higher $\mathrm{pKa}$ values reported in the literature.

\section{Data Availability}

The characterization data used to support the findings of this study are summarized within the article tables. In addition, the Supplementary Materials include the spectral data of the compounds.

\section{Conflicts of Interest}

The authors declare no conflicts of interest.

\section{Acknowledgments}

The authors thank the Universidad Nacional de Colombia for allowing us to use the equipment for the development of our work. The authors acknowledge the financial support provided by the Vicerrectoría De Investigaciones, Universidad El Bosque (Project PCI 2016-8799).

\section{Supplementary Materials}

The supplementary information features IR-FT, H1NMR, C13-NMR, COSY, HSQC, HMBC spectra of the synthesized compounds and chromatograms of $\mathbf{3 b}$ and $\mathbf{3 e}$ with their respective ee calculation. (Supplementary Materials)

\section{References}

[1] C. Grondal, M. Jeanty, and D. Enders, "Organocatalytic cascade reactions as a new tool in total synthesis," Nature Chemistry, vol. 2, no. 3, pp. 167-178, 2010.

[2] H. M. L. Davies and E. J. Sorensen, "Rapid complexity generation in natural product total synthesis," Chemical Society Reviews, vol. 38, no. 11, p. 2981, 2009.

[3] K. C. Nicolaou and J. S. Chen, "The art of total synthesis through cascade reactions," Chemical Society Reviews, vol. 38, no. 11, p. 2993, 2009.

[4] I. S. Young and P. S. Baran, "Protecting-group-free synthesis as an opportunity for invention," Nature Chemistry, vol. 1, no. 3, pp. 193-205, 2009.

[5] P. G. Bulger, S. K. Bagal, and R. Marquez, "Recent advances in biomimetic natural product synthesis," Natural Product Reports, vol. 25, no. 2, p. 254, 2008.

[6] B. Trost, "The atom economy-a search for synthetic efficiency," Science, vol. 254, no. 5037, pp. 1471-1477, 1991.
[7] P. A. Wender, V. A. Verma, T. J. Paxton, and T. H. Pillow, "Function-oriented synthesis, step economy, and drug design," Accounts of Chemical Research, vol. 41, no. 1, pp. 40-49, 2008.

[8] J. Kim and M. Movassaghi, "Biogenetically inspired syntheses of alkaloid natural products," Chemical Society Reviews, vol. 38, no. 11, p. 3035, 2009.

[9] P. Kotame, B.-C. Hong, and J.-H. Liao, "Enantioselective synthesis of the tetrahydro-6H-benzo[c]chromenes via Domino Michael-Aldol condensation: control of five stereocenters in a quadruple-cascade organocatalytic multicomponent reaction," Tetrahedron Letters, vol. 50, no. 6, pp. 704-707, 2009.

[10] X. Yu and W. Wang, "Organocatalysis: asymmetric cascade reactions catalysed by chiral secondary amines," Organic \& Biomolecular Chemistry, vol. 6, no. 12, p. 2037, 2008.

[11] Y. Wang, H. Lu, and P.-F. Xu, "Asymmetric catalytic cascade reactions for constructing diverse scaffolds and complex molecules," Accounts of Chemical Research, vol. 48, no. 7, pp. 1832-1844, 2015.

[12] K. C. Nicolaou, D. J. Edmonds, and P. G. Bulger, "Cascade reactions in total synthesis," Angewandte Chemie International Edition, vol. 45, no. 43, pp. 7134-7186, 2006.

[13] P. Chauhan, S. Mahajan, and D. Enders, "Achieving molecular complexity via stereoselective multiple domino reactions promoted by a secondary amine organocatalyst," Accounts of Chemical Research, vol. 50, no. 11, pp. 2809-2821, 2017.

[14] Y. Huang, A. M. Walji, C. H. Larsen, and D. W. C. MacMillan, "Enantioselective organo-cascade catalysis," Journal of the American Chemical Society, vol. 127, no. 43, pp. 15051-15053, 2005.

[15] L. F. Tietze, "Domino reactions in organic synthesis," Chemical Reviews, vol. 96, no. 1, pp. 115-136, 1996.

[16] I. Oroz-Guinea and E. García-Junceda, "Enzyme catalysed tandem reactions," Current Opinion in Chemical Biology, vol. 17, no. 2, pp. 236-249, 2013.

[17] M. T. Reetz, "Biocatalysis in organic chemistry and biotechnology: past, present, and future," Journal of the American Chemical Society, vol. 135, no. 34, pp. 12480-12496, 2013.

[18] Y. Wang, H. Ren, and H. Zhao, "Expanding the boundary of biocatalysis: design and optimization ofin vitrotandem catalytic reactions for biochemical production," Critical Reviews in Biochemistry and Molecular Biology, vol. 53, no. 2, pp. 115-129, 2018.

[19] Y. Wang and H. Zhao, "Tandem reactions combining biocatalysts and chemical catalysts for asymmetric synthesis," Catalysts, vol. 6, no. 12, p. 194, 2016.

[20] J. Muschiol, C. Peters, N. Oberleitner, M. D. Mihovilovic, U. T. Bornscheuer, and F. Rudroff, "Cascade catalysis-strategies and challenges en route to preparative synthetic biology," Chemical Communications, vol. 51, no. 27, pp. 5798-5811, 2015.

[21] H. Clavier and H. Pellissier, "Recent developments in enantioselective metal-catalyzed domino reactions," Advanced Synthesis \& Catalysis, vol. 354, no. 18, pp. 3347-3403, 2012.

[22] H. Pellissier, "Chapter 2. Asymmetric domino reactions based on the use of chiral metal catalysts," in Asymmetric Domino Reactions, p. 150, Royal Society of Chemistry, London UK, 2013.

[23] D. Enders, C. Grondal, and M. R. M. Hüttl, "Asymmetric organocatalytic domino reactions," Angewandte Chemie International Edition, vol. 46, no. 10, pp. 1570-1581, 2007.

[24] M. Nielsen, D. Worgull, T. Zweifel, B. Gschwend, S. Bertelsen, and K. A. Jørgensen, "Mechanisms in aminocatalysis," Chemical Communications, vol. 47, no. 2, pp. 632-649, 2011. 
[25] C. S. Evans and L. O. Davis, "Recent advances in organocatalyzed domino $\mathrm{C}-\mathrm{C}$ bond-forming reactions," Molecules, vol. 23, no. 1, p. 33, 2017.

[26] H. Pellissier and J. J. Spivey, Recent Developments in Asymmetric Organocatalysis; RSC Catalysis Series, The Royal Society of Chemistry, London, UK, 2010.

[27] C. M. R. Volla, I. Atodiresei, and M. Rueping, "Catalytic C-C bond-forming multi-component cascade or domino reactions: pushing the boundaries of complexity in asymmetric organocatalysis," Chemical Reviews, vol. 114, no. 4, pp. 2390-2431, 2014.

[28] M. Rueping, E. Sugiono, and E. Merino, "Asymmetric organocatalysis: an efficient enantioselective access to benzopyranes and chromenes," Chemistry-A European Journal, vol. 14, no. 21, pp. 6329-6332, 2008.

[29] P. I. Dalko and L. Moisan, "In the golden age of organocatalysis," Angewandte Chemie International Edition, vol. 43, no. 39, pp. 5138-5175, 2004.

[30] P. I. Dalko and L. Moisan, "Enantioselective organocatalysis," Angewandte Chemie International Edition, vol. 40, no. 20, pp. 3726-3748, 2001.

[31] P. Melchiorre, M. Marigo, A. Carlone, and G. Bartoli, "Asymmetric aminocatalysis-gold rush in organic chemistry," Angewandte Chemie International Edition, vol. 47, no. 33, pp. 6138-6171, 2008.

[32] S. G. Ouellet, A. M. Walji, and D. W. C. Macmillan, "Enantioselective organocatalytic transfer hydrogenation reactions using hantzsch esters," Accounts of Chemical Research, vol. 40, no. 12, pp. 1327-1339, 2007.

[33] F.-L. Zhang, A.-W. Xu, Y.-F. Gong, M.-H. Wei, and X.-L. Yang, "Asymmetric organocatalytic four-component quadruple domino reaction initiated by oxa-michael addition of alcohols to acrolein," Chemistry-A European Journal, vol. 15, no. 28, pp. 6815-6818, 2009.

[34] D. Enders, R. Krüll, and W. Bettray, "Microwave-assisted organocatalytic quadruple domino reactions of acetaldehyde and nitroalkenes," Synthesis, vol. 2010, no. 4, pp. 567-572, 2010.

[35] D. Enders, M. R. M. Hüttl, C. Grondal, and G. Raabe, “Control of four stereocentres in a triple cascade organocatalytic reaction," Nature, vol. 441, no. 7095, pp. 861-863, 2006.

[36] S. Duce, I. Alonso, A. M. Lamsabhi et al., "The acidity of a carbon nucleophile dictates enantioselectivity and reactivity in Michael additions to aromatic and aliphatic enals via iminium activation," ACS Catalysis, vol. 8, no. 1, pp. 22-34, 2018.

[37] J. O. Guevara-Pulido, J. M. Andrés, and R. Pedrosa, “The organocatalyzed domino Michael-aldol reaction revisited. Synthesis of enantioenriched 3-hydroxycyclohexanone derivatives by reaction of enals with $\alpha, \alpha^{\prime}$-diaryl-substituted acetone," RSC Advances, vol. 5, no. 81, pp. 65975-65981, 2015.

[38] J. O. Guevara-Pulido, J. M. Andrés, and R. Pedrosa, "Organocatalytic domino michael-heterocyclization reaction of $\alpha$, $\beta$-unsaturated aldehydes and $\alpha$-cyano ketones: synthesis of enantioenriched 4,5,6-trisubstituted 3,4-dihydropyranones," European Journal of Organic Chemistry, vol. 2014, no. 36, pp. 8072-8076, 2014.

[39] J. O. Guevara-Pulido, J. M. Andrés, and R. Pedrosa, “One-pot sequential organocatalytic michael-tishchenko-lactonization reactions. Synthesis of enantioenriched 4,5,6-trisubstituted $\delta$-lactones," The Journal of Organic Chemistry, vol. 79, no. 18, pp. 8638-8644, 2014.

[40] D. A. Alonso, S. Kitagaki, N. Utsumi, and C. F. Barbas, "Towards organocatalytic polyketide synthases with diverse electrophile scope: trifluoroethyl thioesters as nucleophiles in organocatalytic Michael reactions and beyond," Angewandte Chemie International Edition, vol. 47, no. 24, pp. 4588-4591, 2008.

[41] M. Tiecco, A. Carlone, S. Sternativo, F. Marini, G. Bartoli, and P. Melchiorre, "Organocatalytic asymmetric $\alpha$-selenenylation of aldehydes," Angewandte Chemie International Edition, vol. 46, no. 36, pp. 6882-6885, 2007.

[42] A. Carlone, S. Cabrera, M. Marigo, and K. A. Jørgensen, "A new approach for an organocatalytic multicomponent domino asymmetric reaction," Angewandte Chemie International Edition, vol. 46, no. 7, pp. 1101-1104, 2007.

[43] M. Marigo, S. Bertelsen, A. Landa, and K. A. Jørgensen, "Onepot organocatalytic domino michael-aldol and intramolecular SN2 reactions. Asymmetric synthesis of highly functionalized epoxycyclohexanone derivatives," Journal of the American Chemical Society, vol. 128, no. 16, pp. 5475-5479, 2006.

[44] J. O. Guevara-Pulido, J. M. Andrés, D. P. Ávila, and R. Pedrosa, "Enantioselective synthesis of seven-membered carbo- and heterocyles by organocatalyzed intramolecular Michael addition," RSC Advances, vol. 6, no. 36, pp. 3016630169, 2016. 